\title{
Effect of Maleic-Anhydride Grafting on the Properties of Flax Reinforced Polypropylene Textile Composites
}

\author{
Mahmudul H. Akonda1, Hassan M. El-Dessouky ${ }^{2,3^{*}}$ \\ ${ }^{1}$ Aerospace Research Institute, University of Manchester, Manchester, UK \\ ${ }^{2}$ Department of Physics, Faculty of Science, Mansoura University, Mansoura, Egypt \\ ${ }^{3}$ Composite Centre, Advanced Manufacturing Research Centre (AMRC), University of Sheffield, Sheffield, UK \\ Email: ‘h.el-dessouky@sheffield.ac.uk, ‘hassanoptics@yahoo.com
}

How to cite this paper: Akonda, M.H. and El-Dessouky, H.M. (2019) Effect of Maleic-Anhydride Grafting on the Properties of Flax Reinforced Polypropylene Textile Composites. Journal of Textile Science and Technology, 5, 69-85.

https://doi.org/10.4236/jtst.2019.54007

Received: July 6, 2019

Accepted: September 7, 2019

Published: September 10, 2019

Copyright $\odot 2019$ by author(s) and Scientific Research Publishing Inc. This work is licensed under the Creative Commons Attribution International License (CC BY 4.0).

http://creativecommons.org/licenses/by/4.0/

(c) (i) Open Access

\begin{abstract}
The use of maleic anhydride (MA) coupling agent in polypropylene (PP) matrix system is promising technique to enhance the fibre-matrix interface in composite applications. However, most of the previous studies are focused on either treatment of the natural fibres or the PP matrix with this coupling agent, which are not commercially viable. In this work, a cost-effective technique "hybrid yarns" was used to manufacture commingled reinforcing flax fibres and MA-grafted PP matrix fibres. Two types of twist-less flax/PP and flax/MAPP hybrid yarns were produced containing $40 \%$ flax and $60 \%$ matrix fibres by volume. Both PP and MAPP fibres were thermally and rheologically characterised using DSC, MFI, TGA, DTA and capillary rheometer. It is found that the composites manufactured from flax/MAPP blends exhibited $15 \%$ higher strength and $25 \%$ higher modulus compared to those made of flax/PP. This was due to the improved flax/matrix interface, the higher melt flow rate and lower share viscosity behaviour of the MAPP matrix fibres compared to the standard PP fibres used.
\end{abstract}

\section{Keywords}

Natural Fibre, Thermoplastic, Commingled Yarn, Composite,

Mechanical Properties

\section{Introduction}

Recent studies show that natural fibres have some remarkable advantages such as renewability (come from non-food-based agricultural plants), $\mathrm{CO}_{2}$ neutral, ${ }^{\star}$ Both authors are contributed equally, i.e. joint first author. 
bio-degradability, easy to recycle compared to widely-used glass and carbon fibres in composite industries. Therefore, thermoplastic composites, especially made from bast fibres (long fibres) such as flax, jute, hemp are becoming popular in recent years in structural and semi-structural applications due to their attractive low densities $\left(1.4-1.5 \mathrm{~g} / \mathrm{cm}^{3}\right)$ and high specific strength, compared to particularly E-glass fibres, for example, the specific modulus for E-glass and flax are $29 \mathrm{GPa}$ and 30 - $46 \mathrm{GPa}$, respectively [1]. Moreover, thermoplastic yarns and fabrics from those fibres have been drawn a considerable interest, nowadays, due to rapid composite molding processing, easy handling and longer storage life compared to the thermoset resin based natural fibre composites [1].

The reinforcing efficiency of natural fibres depends on their compositions, fibre structures and the nature of matrix used. Due to the limitation on degradation temperature (started from $220^{\circ} \mathrm{C}$ ) of cellulosic fibres [2] [3], the selection of thermoplastic matrixes is limited. Moreover, natural fibres contain $18 \%-20 \%$ hemi-cellulose and 5\% - 10\% lignin, which start to decompose from $200^{\circ} \mathrm{C}$ and $170^{\circ} \mathrm{C}$, respectively [2]. Therefore, only a few thermoplastic matrices with lower melting temperature $\left(130^{\circ} \mathrm{C}-170^{\circ} \mathrm{C}\right)$ such as polylactic acid (PLA), co-polyester (co-PET), polypropylene (PP), polyethylene (PE), polyamide (PA), and polyhydroxy butyrate (PHB) are found to be compatible with natural fibres [4]. Among these matrices, PP is found to be the widely-used matrix due to low price, low density, moderate strength (ultimate tensile strength 30 - $35 \mathrm{MPa}$ ) and stiffness (modulus $1.8 \mathrm{GPa}$ ) and good chemical resistant properties. However, the hydrophilic nature of the natural fibres, which is due to the existence of $\mathrm{OH}$ group on the surface, makes them incompatible with hydrophobic PP thermoplastics matrices [5] [6] and therefore, the better fibre-matrix interface was not achieved.

Therefore, fibre or matrix modification is necessary to improve their compatibility. Surface treatment or surface modification of natural fibres are common techniques that can be done by either treating the natural fibre by compatibilizer like acetylation [7] [8] [9] where surface $\mathrm{OH}$ groups are covalently bonded with acetyl groups $\left(\mathrm{CH}_{3} \mathrm{CO}\right)$ aiming to establish more intimate contact between fibre and PP matrix. However, this technique promotes interatomic fibre/matrix adhesion by weak van der Waals forces [9] [10]. Another option "grafting of compatibilizer into fibres" has been investigated [11] [12] [13] to create stronger bond between the fibre and PP matrix [10]-[14]. In those cases, fibres were treated with coupling agents like maleic anhydride (MA) and dried prior to composites manufacturing. In another work, bonding between the lignin-based fibres and the PP polymer were found to be weaker when a compatibilizer was not applied [11] [12] [13]. It was also reported that the anhydride groups of male ated coupling agents reacted with the PP thermoplastic matrices and also reacted with hydroxyl groups $(\mathrm{OH})$ at the fibre surface to form intermolecular covalent and hydrogen bonds (Figure 1) [14] [15]. Although, wet treatment with coupling agents is well-accepted approach to improve the natural fibre-matrix adhesion but they are wet processes and require additional drying step, therefore 


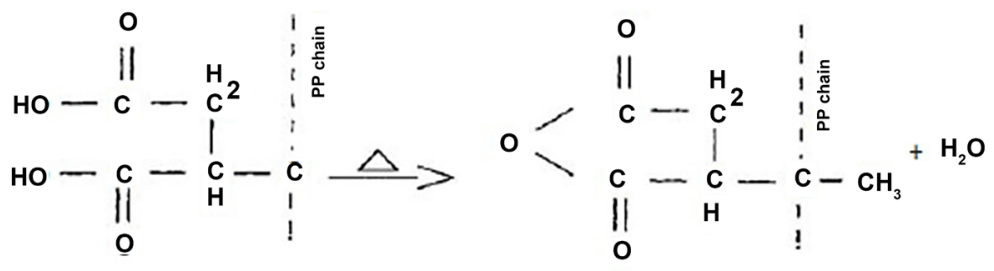

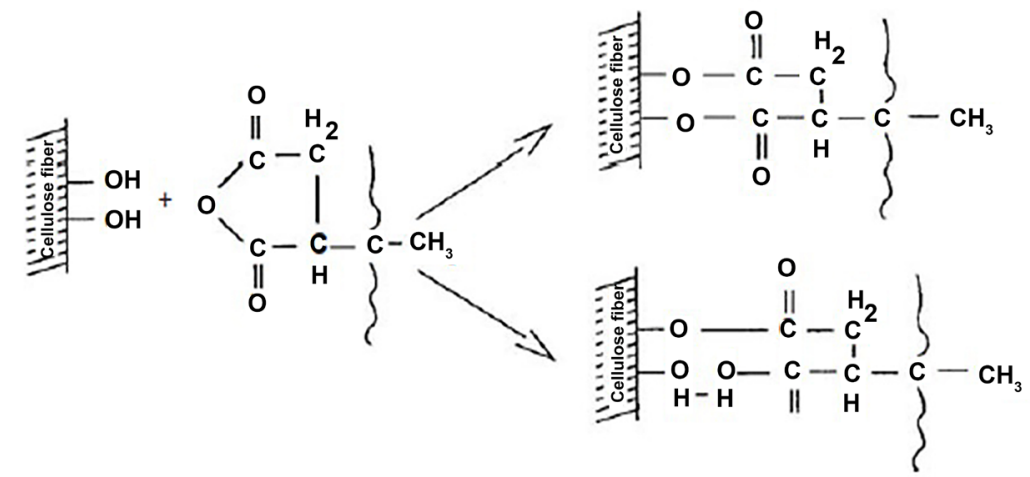

Figure 1. Mechanism of interaction of cellulose fibres with MAPP [14].

such processes are expensive. Moreover, due to heterogeneous and inconsistent in the chemical structure of the natural fibres, the surface modification of natural fibres by the wet process is less controllable.

Recently, alternative cost-effective approach such as matrix modification has been strongly considered [16] instead of surface treatment of the fibres, where grafting of compatibilizer or coupling agents such as maleic anhydride (MA) were grafted onto thermoplastic matrix system to increase the fibre-matrix adhesion. It was found that the adhesion between the natural fibre and MA grafted PP matrix (MAPP) has been improved and a better fibre-matrix bonding has been achieved in the composites developed [17]. It is also reported [17] that the modified PP matrix system with small amount (1\% - 3\%) of MA coupling agents can significantly enhance the fibre-matrix interface leading to better mechanical properties of natural fibres composites. Due to the lower surface energy of MAPP and the good wettability acquired, a good impregnation of the natural fibres could be achieved during hot compaction and consolidation. It is also reported [17] that MA coupling agents applied onto PP system provided stronger linkage in the natural fibre-matrix interface by reducing the surface tension. This mechanism is also established by many modern techniques such as soft X-ray Near Edge Absorption Fine Structure (NEXAFS), where the adhesion and the bonding at the interface regions of flax-MAPP matrix were investigated. It was found that the spectra of flax/MAPP interface have a prominent peak at $285.2 \mathrm{eV}$ $(\mathrm{C}=\mathrm{C})$ and $286.6 \mathrm{eV}(\mathrm{C}=\mathrm{O})$ compared to flax/PP interface [17], hence better impregnation and bonding of MAPP matrix with flax fibres were obtained.

Therefore, there is a demand to adopt a new cost-saving technology for using of MA grafted PP fibres with untreated natural fibres to obtained better me- 
chanical properties of composites. In previous work, flax/PP hybrid thermoplastic yarns and fabrics were treated by MA coupling agent [18] before hot-pressing but those were preliminary investigations and not economically feasible as they are wet processes, which require additional cost for drying after the treatment of the fabrics.

In this work, thermoplastic fibre/fabric (matrix) treatment before composite molding was avoided by using MAPP matrix fibres directly into the composite yarn system. New flax/matrix hybrid commingled yarns are produced using high melt-flow maleic anhydride grafted polypropylene matrix (MAPP) fibres. Composite panels made of flax/MAPP yarns were manufactured and their properties are compared with composites made from standard (untreated) flax/PP matrix. Various analytical techniques, such as DSC, MFI, TGA, DTA and rheometer were used to characterise PP, MAPP fibres and the natural composites produced.

\section{Materials}

The untreated flax fibre (Figure 2(a)) was used as reinforcing fibre. The flax fibres were sourced from Procotex (Belgium). Two types of thermoplastic fibres were used as matrix (Figure 2(b)); standard grad polypropylene (PP) and maleic anhydride grafted polypropylene (MAPP). Both (PP and MAPP) fibres are commercially available and were sourced from Asota $\mathrm{GmbH}$ (Austria) and the \% of active maleic anhydride (MA) in the PP system was undisclosed by the fibre manufacturer. For their comparison studies in composites performance, the same content of flax fibres (\% volume) was reinforced into both matrices. The average length in $\mathrm{mm}$ and linear density in dtex of flax and polypropylene fibres are $90 \pm 15,7.0$ and $90 \pm 5,3.3$, respectively. Prior to composites fabrication, twist-less spun yarns of flax/PP fibres were produced (see Figure 2(c)) using a conventional wrap spinning process to avoid fibre twist in yarns structure [19].

\section{Experimental Work}

\subsection{DSC and MFI Measurements of Matrix Fibres}

The melting point and crystallinity of both PP and MAPP fibres were determined by differential scanning calorimetry (DSC). The melt flow index (MFI) of both matrix fibres was also measured according to ASTM D1238 standard and the tests were performed at $190^{\circ} \mathrm{C}$ to avoid the thermal degradation.

\subsection{Thermal Analysis of PP and MAPP Fibres}

Thermal gravimetric analysis (TGA) and differential thermal analysis (DTA) were carried out on both PP and MAPP fibres in order to observe the thermal behaviour of the matrices. Samples of $5.0 \pm 0.1 \mathrm{mg}$ were taken from each specimen and an STD2606 (TA Instruments) thermal analyser was used under flowing air $(100 \mathrm{ml} / \mathrm{min})$ with a heating rate of $10^{\circ} \mathrm{C} \cdot \mathrm{min}^{-1}$.

\subsection{Rheology of Matrix Fibres}

Capillary rheometer (RH2000, Bohlin Instruments) was used to determine the 


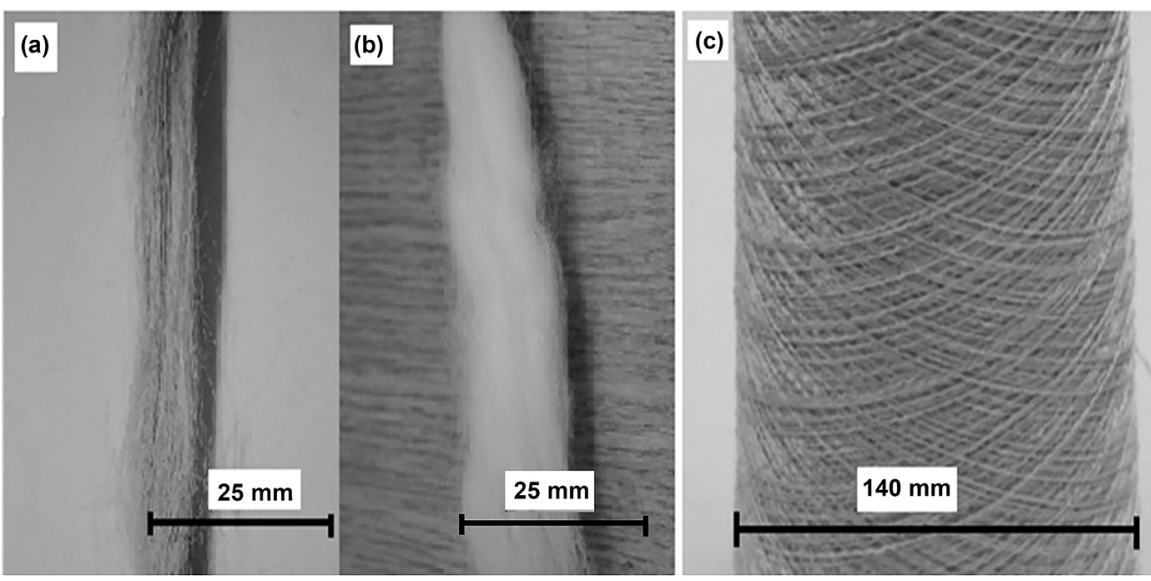

Figure 2. Photographs of flax fibres (a), staple MAPP fibres (b) and flax/MAPP commingled yarn (c).

viscoelastic properties of PP and MAPP fibres. Both fibres were chopped into $\leq 5$ $\mathrm{mm}$ length to be fed into the capillary barrel of the rheometer for melt extrusion and shear viscosity measurements. The diameter of the capillary was $22 \mathrm{~mm}$ with $280 \mathrm{~mm}$ length and $1 \mathrm{~mm}$ diameter die was used. The barrel zone and die temperature profile were maintained at $230^{\circ} \mathrm{C}$. The mass output and pressure drop across the die was measured to determine the shear/melt viscosity versus shear rate.

\subsection{Tensile Properties of Matrices}

The tensile properties of the PP and MAPP matrices were determined by testing PP and MAPP plaques in accordance with BS EN ISO 527-1:1996. The plaques were made with $100 \% \mathrm{PP}$ and MAPP fibres by hot-press moulding at $185^{\circ} \mathrm{C}$ for 5 minutes at 30 bar pressure.

\subsection{Assessment of Flax/Matrix Fibre Blends}

Optical cross-sections of the flax/matrix fibres were prepared to assess the blend quality and to do so samples of fibres/yarns (after removing wrapping filaments) were embedded into epoxy resin and cured. The cured specimens were polished, washed examined using optical microscope. The total number of flax and matrix fibres was counted in per unit area. Optical analytical technique was used to measure the flax fibre orientation in the blended samples and also the yarn waviness. Yarn's strength was also measured according to BS EN ISO 2062:2010 standard.

\subsection{Composites Manufacturing}

Two types of composite panels (yarn unidirectional and yarn woven fabric) were fabricated. For unidirectional (UD) yarn composites, the yarns were wound (12 layers) onto a steel frame $350 \mathrm{~mm} \times 350 \mathrm{~mm}$ in $0^{\circ} / 0^{\circ}$ placement. For woven fabric panels, six plies of plain-weave fabrics $(1 \times 1$ structure, areal weight: $420 \pm 10$ 
$\left.\mathrm{g} / \mathrm{m}^{2}\right)$ in $\left[0 / 90^{\circ}\right]_{6}$ directions were used to manufacture composite panels of $2 \mathrm{~mm}$ nominal thickness. For consolidation process, a hot-press moulding technique at $185^{\circ} \mathrm{C}$ and 50 bars pressure for 5 minutes dwell time was used in all cases. The details of composite samples include their density and porosity, manufactured in this work, are given in Table 1.

\subsection{Composites Testing}

Density, fibre volume fraction and void content:

The composite experimental density $\left(\rho_{\mathrm{c}}\right)$ was measured via Equation (1) and in accordance with ASTM D792 Method A (zeroed pan immersion).

$$
\rho_{c}=\frac{W_{\text {air }}}{W_{\text {air }}-W_{\text {liquid }}} \times \rho_{\text {liquid }}
$$

where, $W_{\text {air }}$ is the weight, in gms, of the specimen in air, $W_{\text {liquid }}$ is the weight, in gms, of the specimen in the immersion liquid and $\rho_{\text {liquid }}$ is the density $\left(\mathrm{g} / \mathrm{cm}^{3}\right)$ of the immersion liquid. The composite (approximately $1.0 \mathrm{gm}$ ) specimens were dried for $24 \mathrm{~h}$ at $100^{\circ} \mathrm{C}$ prior to the density measurement. The theoretical density was also calculated from the densities of fibres and matrices and their mass fractions using Equation (2)

$$
\rho_{t}=\frac{\rho_{f} \rho_{m}}{\rho_{f} m_{m}+\rho_{m} m_{f}}
$$

where, $\rho_{f}$ is flax fibre density $\left(1.5 \mathrm{~g} / \mathrm{cm}^{3}\right) \rho_{m}$ is matrix density $\left(0.91 \mathrm{~g} / \mathrm{cm}^{3}\right) m_{f}$ and $m_{m}$ the mass fraction of fibres and matrix, respectively. For flax mass fraction measurement, representative composite specimens were immersed in Oxyline solvent at $150^{\circ} \mathrm{C}$ for 3 hours to completely dissolve the PP and MAPP matrix to follow ASTM D5492 standard. After cooling the liquid and fibres were filtered, washed several times with distilled water and acetone and finally dried at $100^{\circ} \mathrm{C}$ for 2 hours.

The fraction of voids remaining in the laminates after consolidation was determined as follows:

$$
V=\frac{\rho_{t}-\rho_{c}}{\rho_{t}}
$$

Table 1. Details of the yarns and plain woven fabrics and fabricated composites. All the prepreg materials contain $40 \%$ flax fibres by volume.

\begin{tabular}{ccccc}
\hline Fibre/matrix & Dry Prepreg & Composite ID & $\begin{array}{c}\text { Composite } \\
\text { density }\left(\mathrm{g} / \mathrm{cm}^{3}\right)\end{array}$ & $\begin{array}{c}\text { Voids } \\
\text { content (\%) }\end{array}$ \\
\hline Flax/PP & Yarn (250 tex $)$ & Flax/PPYUD & 1.05 & 6.2 \\
& $\begin{array}{c}\text { Yarn woven fabric } \\
\left(420 \mathrm{~g} / \mathrm{m}^{2}\right)\end{array}$ & Flax/PPYWF & 1.04 & 8.1 \\
& $\begin{array}{l}\text { Yarn }(250 \mathrm{tex}) \\
\text { Flax/MAPP }\end{array}$ & Flax/MAPPYUD & 1.09 & 3.2 \\
& $\begin{array}{c}\text { Yarn woven fabric } \\
\left(420 \mathrm{~g} / \mathrm{m}^{2}\right)\end{array}$ & Flax/MAPPYWF & 1.09 & 3.3 \\
\hline
\end{tabular}




\section{Tensile and flexural properties.}

Five test specimens, $250 \mathrm{~mm} \times 25 \mathrm{~mm}$, were cut from the composite panels produced for tensile measurements (BS EN ISO 527-1:1996), and a further 5 (60 $\mathrm{mm} \times 15 \mathrm{~mm} ; 40 \mathrm{~mm}$ span length) for flexural properties (ISO 14125), accordingly the tensile and flexural strengths and moduli of specimens were determined.

\section{Results and Discussion}

\subsection{Fibre-Matrix Blends}

To keep the flax fibre straight (twist-less) and aligned to the yarn axis in the hybrid yarn structure, the wrap spun yarn technique was used where the mean flax fibre inclination angle $\left(\theta_{\text {mean }}=0^{\circ}\right)$ was considered zero degree in this yarn. In twisted yarn structure, the $\theta_{\text {mean }}$ was estimated $21^{\circ}$ from Equation (4) [20], and due to the fibre inclination, the optimum load transfer effect from matrix to the fibres could not be achieved [21].

$$
\theta_{\text {mean }}=\theta_{r}+\frac{\theta_{r}}{\tan ^{2} \theta_{r}}-\frac{1}{\tan \theta_{r}} \theta_{r}
$$

where, $\theta_{r}$ is the twist angle of fibres on twisted yarn, which was estimated to be $30^{\circ}$.

To avoid fibre twist in new yarn structure, the flax and matrix fibres (PP and MAPP) were commingled by using 50/47\% (flax/matrix fibre) weight ratios and extra 3\% matrix continuous filaments of matrix fibres were wrapped in yarn production process to produce $50 / 50 \%$ weight ratios in the final yarn samples. The 50:50 weight fractions were selected to achieve the highest wettability of the flax fibres in composites [3] as higher amount of matrix fibres in yarn reduces the flax fibre-volume fraction in yarn, which can be explained by Equations (5) and (6).

$$
\begin{gathered}
V_{\text {Flax }}=B_{\text {Flax }} V_{f} \\
V_{\text {Matrix }}=B_{\text {Matrix }} V_{f}
\end{gathered}
$$

where, $V_{f}$ is the total fibre volume fraction of both fibres in yarn. $B$ is the weight fraction.

For 50:50 weight ratio, $B_{\text {Flax }}+B_{\text {Matrix fibres }}=1$, so that the total $3 \%$ of filaments in the yarns were used as the core blends of yarn (flax/matrix, 50/47\% by wt) were fixed. It was also found by researchers that the filament turns/m influences the total matrix weight fraction in the yarn structure [18]. In this work, it was found that filament wrapping angle has influenced the yarn strength, where the average breaking loads of $19.5 \mathrm{~N}$ with breaking extension of $5.5 \%$ were found for $44.6^{\circ}$ wrapping angle. Lower yarn strength $(10.5 \mathrm{~N})$ was found for the yarns produced using $32.4^{\circ}$ angle. It was due to changing of filaments wrapping angle from $44.6^{\circ}$ to $32.4^{\circ}$ (Figure 3(a)) made the yarns structurally weak resulting in the lower yarn strength as the number of turns/ $\mathrm{m}$ was reduced. Therefore, filaments were wrapped at $44.6^{\circ}$ angle from the yarn axis (Figure 3(b)) to retain $50 \%$ flax weight fraction in both yarns, which was confirmed by matrix dissolution test. 

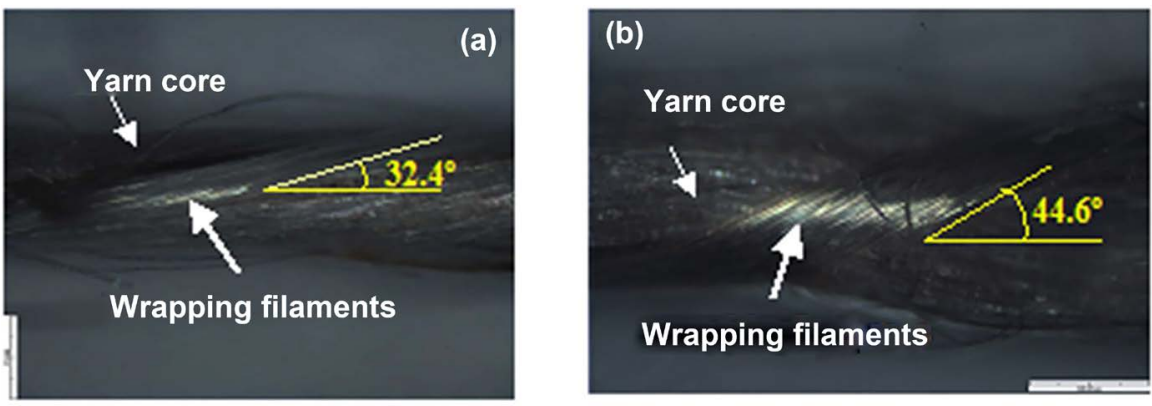

Figure 3. Images of wrapping filaments in yarn structure at (a) $32.4^{\circ}$ and (b) $44.6^{\circ}$.

On the other hand, longer flax fibres (mean fibre length: $90 \mathrm{~mm}$ ) were selected to achieve better reinforcing effect of flax fibres in the matrix and to enhance the load transfer effect, which can be explained by the Equation (7).

$$
E_{L}=\left[B_{\text {Flax }} E_{\text {Flax }}+\left(1-B_{\text {Flax }}\right) E_{\text {Flax }}\right] \eta_{l} \eta_{l \theta}
$$

where, $E_{L}$ is longitudinal tensile modulus of the composites, $E_{\text {Flax }}$ and $E_{\text {Matrix }}$ are the tensile moduli of flax and matrix, respectively. $\eta_{I}$ is called length efficiency factor of the flax fibres and $\eta_{1 \theta}$ is called fibre orientation factor which representing the flax alignment in the composite.

The fibre orientation factor and fibre length efficiency factor are interlaced in case of hybrid yarn processing. Good fibre orientation distribution in yarns structure is affected by the fibre-fibre cohesion between the flax and matrix fibres during commingling process and the optimum fibre alignment $\left(\theta_{\text {mean }}=0^{\circ}\right)$ could be achieved by aligning the long flax and matrix towards yarn axis. Optical microscopy showed that the flax fibres are mostly aligned/oriented towards the yarn axis or the machine direction (MD) (Figure 4). Figure 5 shows a selection of the cross-sectional micrograph of the flax/MAPP blends. The micrographs have been analysed using Image-J software to assess the blend quality and to calculate the flax fibre content in the blend/sliver made from flax/MAPP. Based on the nature of flax fibres that have irregular cross sections, the flax fibres are labelled as 'F' and the round cross-section (polypropylene) fibres as 'P'. Qualitatively it is found that the flax fibres are well blended with matrix polypropylene fibres in yarn produced (Figure 5). Image analysis was carried out for the cross-section micrographs of the flax/MAPP blend (Figure 5). The images selected (Figures 5(a)-(c)) have the same frame size $(143.71 \mu \mathrm{m} \times 107.78 \mu \mathrm{m})$. Based on the cross-sectional areas of both fibres (flax and polypropylene), the average of flax fibre volume fraction was calculated to be $39.21 \% \pm 4.70 \%$ which is in good agreement with the theoretical value (38.56\%). Table 2 gives the summary of image analysis results.

\subsection{Effect of Maleic Anhydride in PP Matrix}

Figure 6 shows the DSC thermograms of PP and MAPP fibres and summary of the results obtained are listed in Table 3. It was found that the melting point is $164.5^{\circ} \mathrm{C}$, crystallinity of $52.5 \%$ for the neat PP fibres. The crystallinity of MAPP 

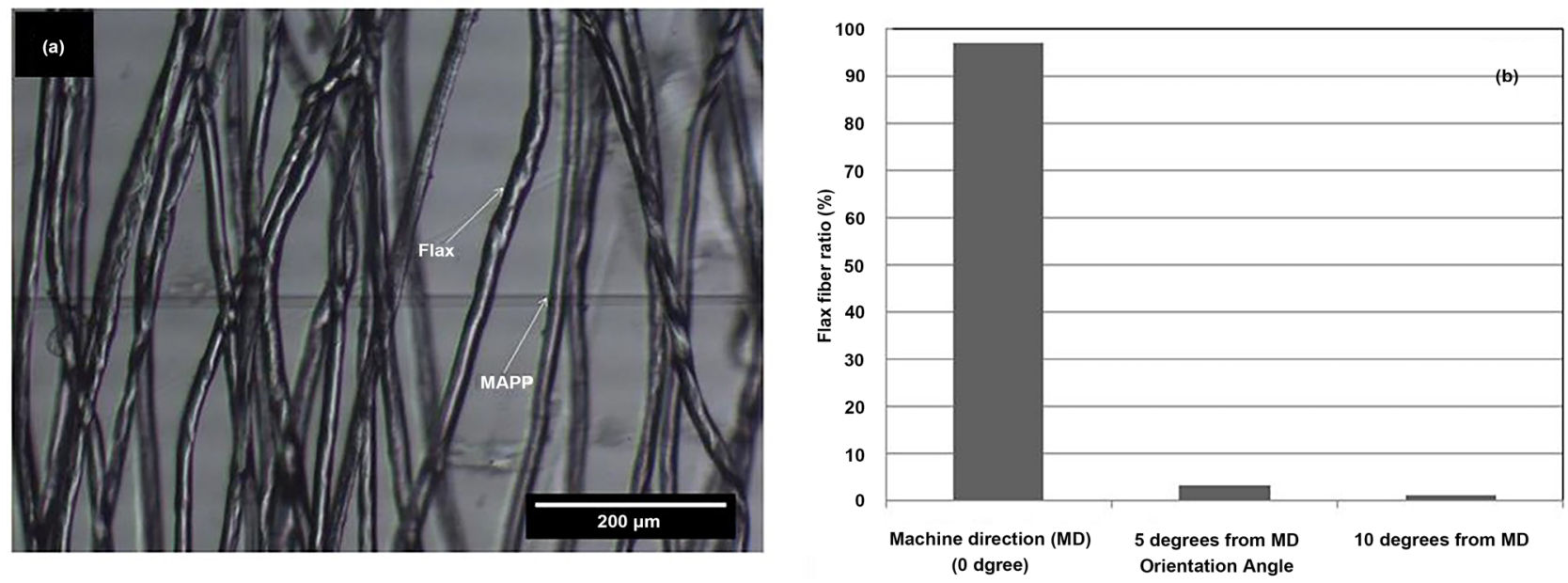

Figure 4. Micrograph of flax/MAPP fibres blend (a) and flax fibres orientation/alignment in yarn produced (b).
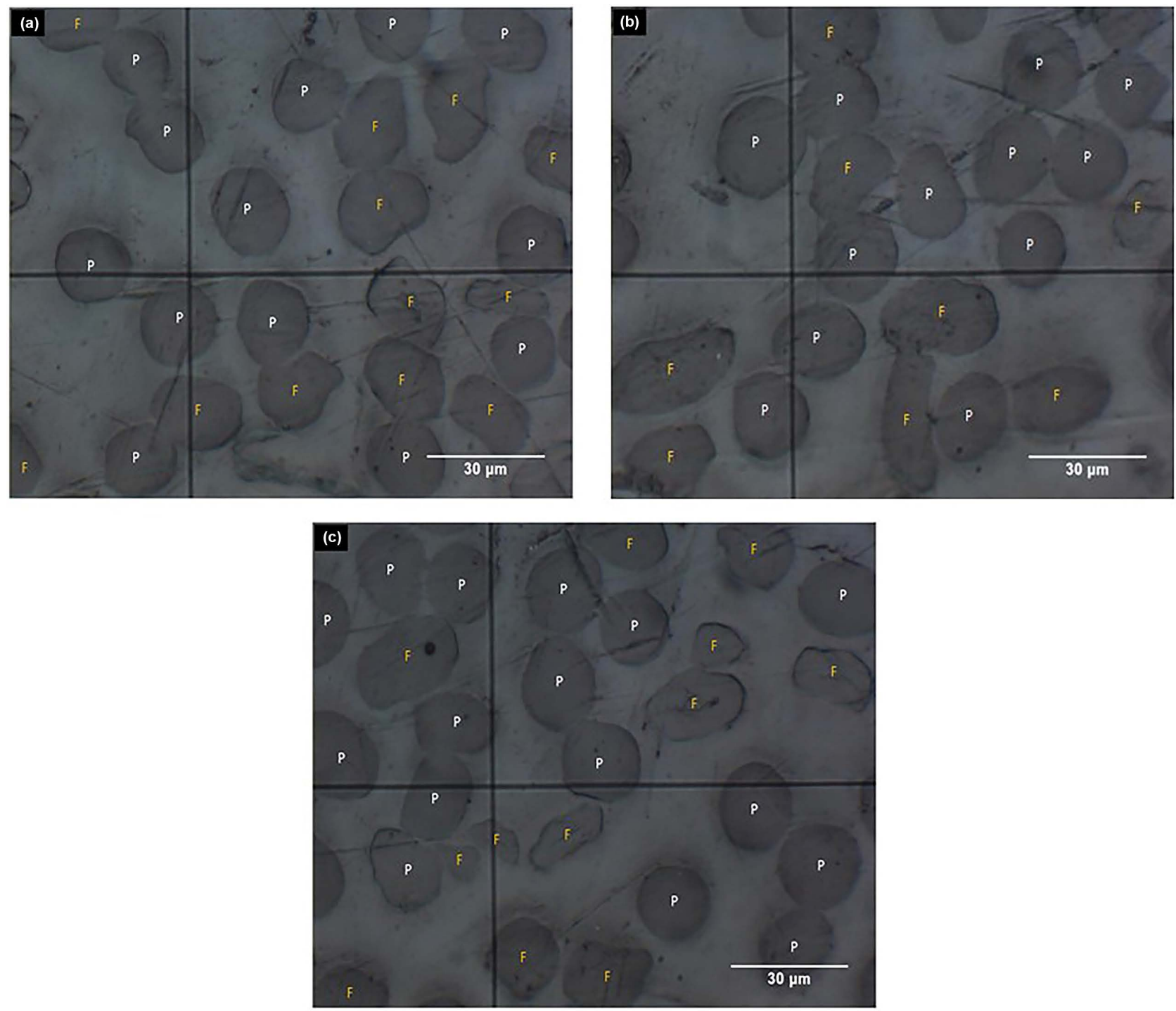

Figure 5. A selection of optical cross-sectional images of flax/PP (50/50 wt \%) commingled blend/sliver; symbols $F$ and $P$ refer to flax and polypropylene fibres. 


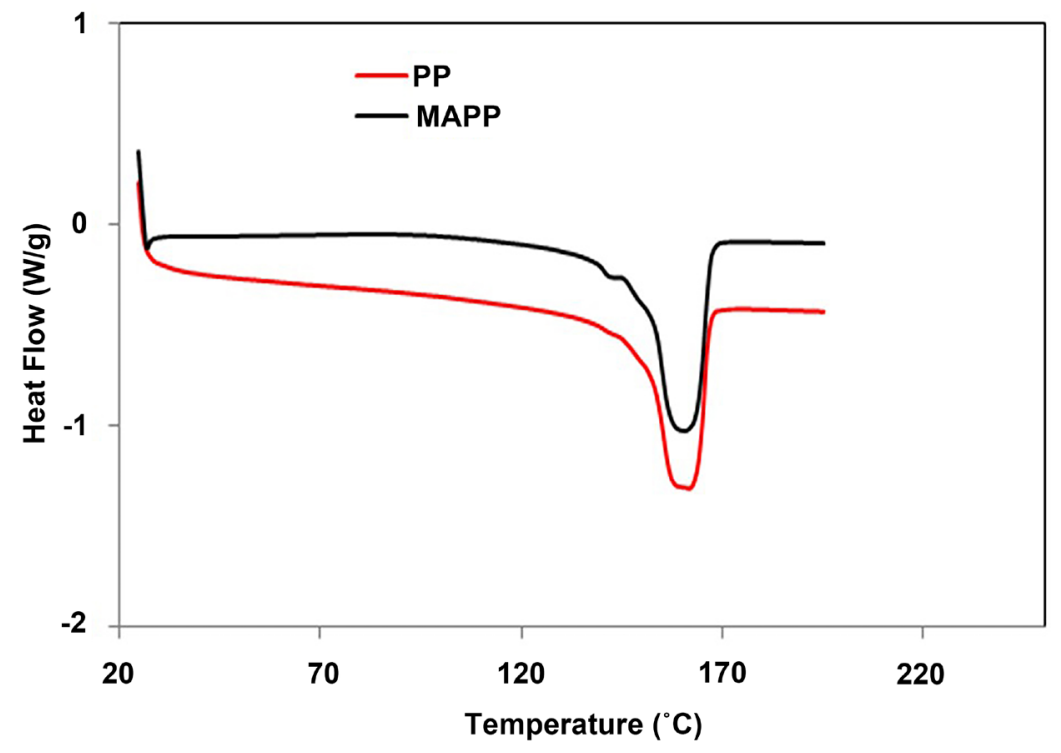

Figure 6. DSC thermograms of PP and MAPP matrix fibres.

Table 2. Image analysis of optical cross-sections (Figure 5) for calculating flax fibres content in the sliver/blend produced (Image frame was $143.71 \mu \mathrm{m} \times 107.78 \mu \mathrm{m}$ ).

\begin{tabular}{cccc}
\hline Image & $\begin{array}{c}\text { Total cross-sectional area of } \\
\text { flax fibres }\left(\mu \mathrm{m}^{2}\right)\end{array}$ & $\begin{array}{c}\text { Total cross-sectional area of } \\
\text { PP fibres }\left(\mu \mathrm{m}^{2}\right)\end{array}$ & $\begin{array}{c}\text { Fibre volume fraction of } \\
\text { flax fibres (\%) }\end{array}$ \\
\hline Figure 5(a) & 2379.50 & 3069.78 & 43.67 \\
Figure 5(b) & 2432.37 & 3698.96 & 39.67 \\
Figure 5(c) & 1979.79 & 3791.92 & 34.30 \\
\multicolumn{2}{c}{ Mean value of flax fibre volume fraction in flax/MAPP blend } & $39.21 \pm 4.70$ \\
\hline
\end{tabular}

Table 3. Thermal properties of PP and MAPP fibres.

\begin{tabular}{ccc}
\hline Property & PP fibres & MAPP fibres \\
\hline DSC-Melting temperature $\left({ }^{\circ} \mathrm{C}\right)$ & $164.5 \pm 0.7$ & $161.9 \pm 2.1$ \\
DSC-Degree of crystallinity $(\%)$ & $50 \pm 1.4$ & $51.8 \pm 6.8$ \\
Melt flow index (MFI) $(\mathrm{g} / 10 \mathrm{~min})$ & $40.2 \pm 7.8$ & $67.8 \pm 2.3$ \\
\hline
\end{tabular}

is $51.8 \%$ which is slightly lower than $\mathrm{PP}$, therefore, the melting temperature of MAPP is found to be slightly lower $\left(161.9^{\circ} \mathrm{C}\right)$ than the PP one. Figure 7 presents the TGA and DTA behaviour of both PP and MAPP matrix fibres. From the DTA curves (Figure 7(b)), the endothermic peaks for both PP and MAPP fibres were found around $170^{\circ} \mathrm{C}$ due to the melting of both polymers and no other peaks were observed up to $280^{\circ} \mathrm{C}$. As the melting is a phase change, no mass losses were observed before the melting points of the polymers but slightly higher mass loss was observed for MAPP fibres compared to PP fibre in the temperature range of $190^{\circ} \mathrm{C}-270^{\circ} \mathrm{C}$ (see Figure $7(\mathrm{a})$ ), which is confirmed that the MAPP fibres are slightly less thermally stable than PP to that temperature range. This is probably due to effect of anhydride group with PP polymer but after $270^{\circ} \mathrm{C}$, the $\%$ mass losses are same for both polymers. 

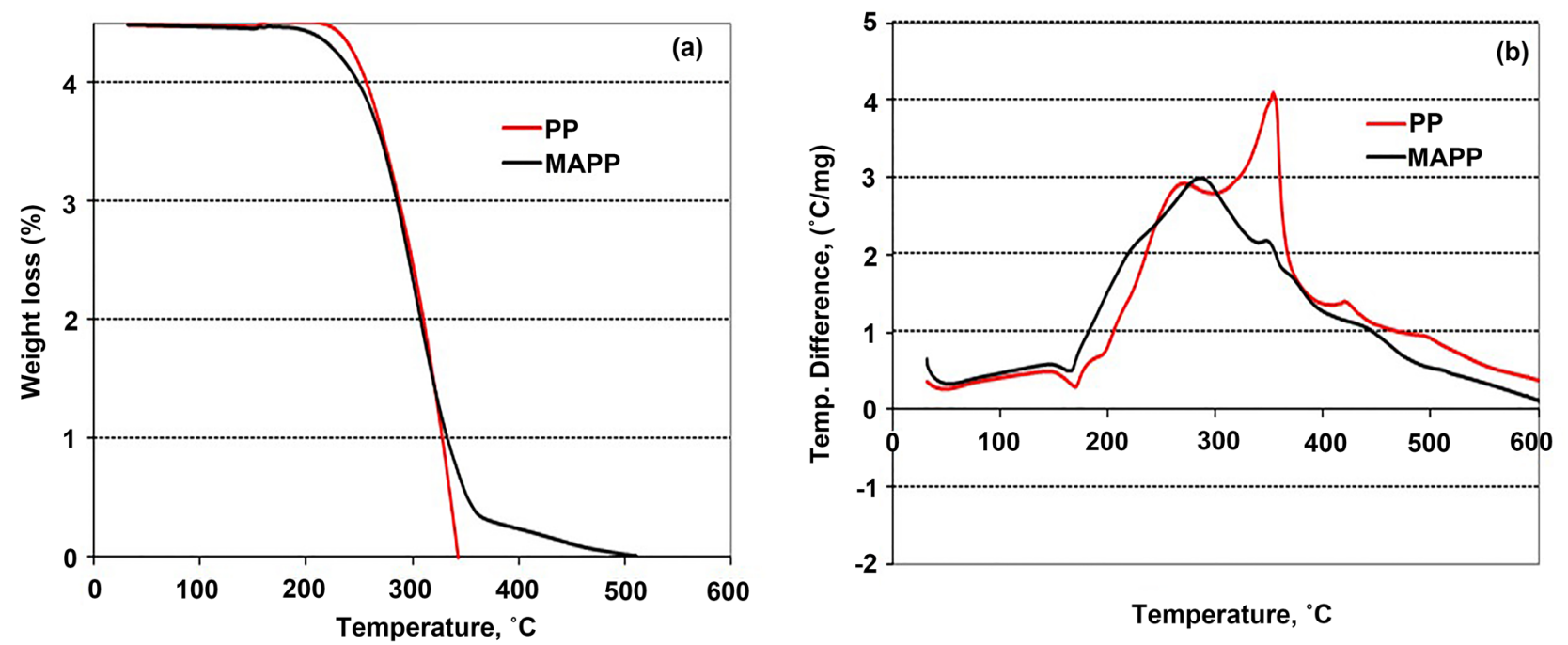

Figure 7. (a) TGA and (b) DTA graphs of PP and MAPP matrix fibres.

The tensile properties of both PP and MAPP matrices without fibre reinforcement were found to be the same (Tensile strength $33.4 \mathrm{MPa}$ and modulus $2.0 \mathrm{GPa}$ ). However, significant difference was also found for both polymers as the melt flow index (MFI) results showed that the MAPP has MFI of $67.8 \mathrm{~g} / 10$ min and $40.2 \mathrm{~g} / 10 \mathrm{~min}$ for the standard PP (see Table 3). The lower melting and the higher MFI of MAPP compared to PP make the thermoplastic resin/matrix flows easily and diffuses well resulting in better wettability/impregnation of reinforcing fibres during the composite consolidation.

In addition, rheological studies of both fibres (MAPP \& PP) were carried out. Figure 8 shows the viscosity-shear rate curves for PP and MAPP resin fibres. It is clear that the shear viscosity of PP initially drops from $225 \mathrm{~Pa}$.s and finally to 50.37 Pa.s within the applied range of shear rate $\left(20-2122 \mathrm{~s}^{-1}\right)$. By comparing this for MAPP it is found that the viscosity drops from 185.40 Pa.s to 33.23 Pa.s within the same range of shear rate. Furthermore, the MAPP fibres exhibited better Newtonian's behaviour compared to standard PP. This implies that the use of MAPP fibres as composite matrix will be processed better than the standard PP, hence improved mechanical properties could be obtained for the composites produced with same consolidation profile.

\subsection{Effect of MA in Composite Properties}

By inspecting the composites made from both flax/PP and flax/MAPP blends, it is observed that the yarn structures were disappeared and the footprint of wrapping filaments was also not found on the panel's surface. The PP fibres in the yarn core (blended with flax) and filament wrappers on the yarn surface were fully melted during consolidation.

Figure 9 showed that the effect of moulding temperatures on flexural modulus of the laminates with constant moulding time $(5 \mathrm{~min})$ and pressure (50 bar) for all samples, It can be seen that at lower temperature $\left(165^{\circ} \mathrm{C}\right)$ the matrices 


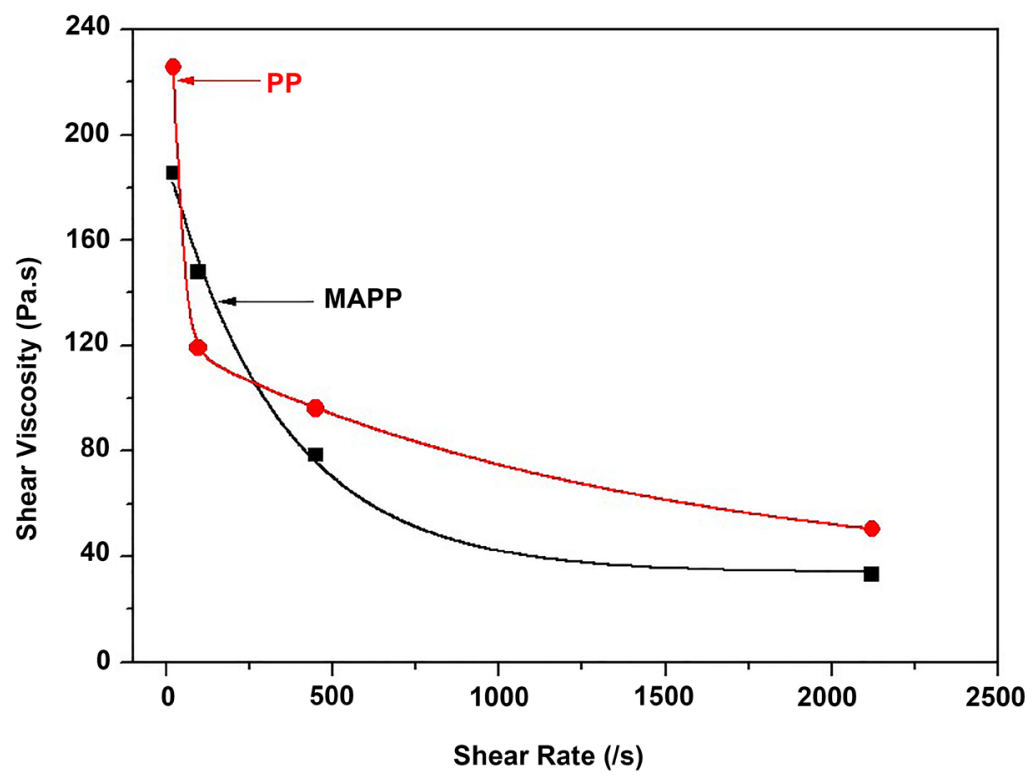

Figure 8. Rheology of PP and MAPP matrix fibres.

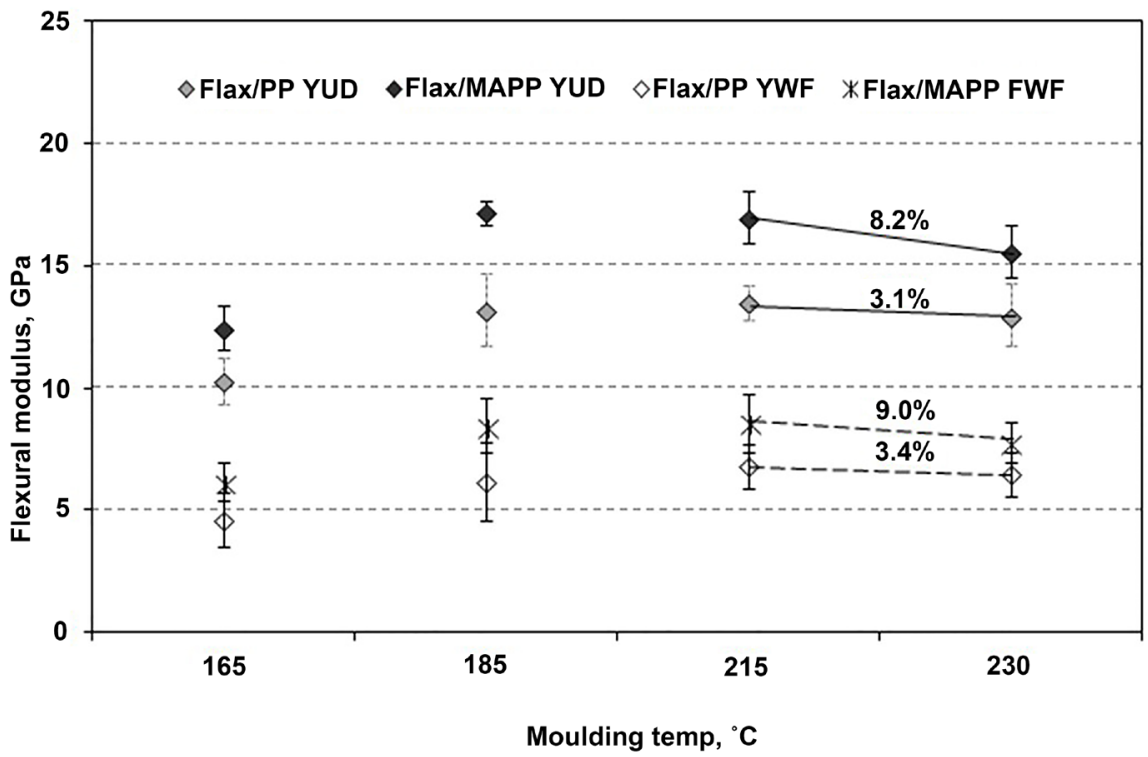

Figure 9. Effect of moulding temperature on flexural modulus of composite laminates produced.

were not fully consolidated resulting in lower flexural modulus of all laminates (Figure 9). At higher temperature $\left(230^{\circ} \mathrm{C}\right)$, the flexural moduli were also lower for all laminates (Figure 9) due to thermal degradation of the natural fibres [2] [3]. It was also seen that the flexural modulus of MAPP composites produced at $230^{\circ} \mathrm{C}$ are $8 \%-9 \%$ lower (Figure 9) compared to those values are found for the laminates produced at $185^{\circ} \mathrm{C}$. This is probably due to the thermal degradation of the MAPP fibres compared to PP at that temperature as found from their TGA curves (Figure 7(a)). Therefore, optimum-processing temperature for composite fabrication was set up at $185^{\circ} \mathrm{C}$ to obtained better mechanical properties of 
the laminates. The tensile and flexural tests have been carried out for the composite samples produced by using optimised moulding conditions at $185^{\circ} \mathrm{C}$ for 5 min moulding time and the summary of the results obtained for both UD yarn and yarn woven fabric composites are presented in Figure 10. It was found that the mean tensile strength was determined to be $121 \mathrm{MPa}$ and $140.5 \mathrm{MPa}$, for flax/PPYUD (flax/PP yarn unidirectional) and flax/MAPPYUD (flax/MAPP yarn unidirectional) composites (Figure 10). The mean flexural strength was found to be 122.0 MPa and 144.2 MPa for flax/PPYUD and flax/MAPPYUD laminates. The mean values of tensile and flexural moduli were found to be 16.3 $\mathrm{GPa}$ and 16.6 GPa for flax/PPYUD composites and 19.5 GPa and 19.2 GPa for flax/MAPPYUD laminates (Figure 10). For yarn is woven fabric composites, the mean tensile and flexural strength were found to be 56.0 MPa and 78.2 MPa for the flax/PPYWF (flax/PP yarn woven fabric) laminates and 70.1 MPa and 94.4 MPa for flax/MAPPYWF composite samples (Figure 10). The tensile and flexural moduli were found to be $8.6 \mathrm{GPa}$ and $6.2 \mathrm{GPa}$ for flax/PPYWF and $11 \mathrm{GPa}$ and $8.1 \mathrm{GPa}$ for flax/MAPPYWF composites respectively (Figure 10).

The theoretical tensile strength and modulus of both yarn unidirectional (UD) composites were calculated according to the role of mixtures via Equations (8) and (9).

$$
\begin{gathered}
\sigma_{C}=\sigma_{C} \cdot \varphi_{F}+\sigma_{M}\left(1-\varphi_{F}\right) \\
\epsilon_{C}=\epsilon_{F} \cdot \varphi_{F}+\epsilon_{M}\left(1-\varphi_{F}\right)
\end{gathered}
$$

where, $\sigma_{C}=$ tensile strength of composite; $\sigma_{F}=$ tensile strength of fibres; $\varphi_{F}=$ fibre volume $\% ; \sigma_{M}=$ tensile strength of matrix; $\epsilon_{C}=$ Young's modulus of composite; $\epsilon_{F}=$ Young's modulus of fibres; $\epsilon_{M}=$ Young's modulus of matrix.

The theoretical tensile strength and Young's modulus of the yarn unidirectional composites were 209.4 MPa and 23.52 GPa. The measured tensile strength was found to be $40 \%$ lower for PP matrix and 30\% lower for MAPP matrix for UD composites respectively (Table 4). Similarly, the measured Young's modulus were found to be $31 \%$ and $17 \%$ lower for PP and MAPP matrix UD composites, respectively (Table 4). The flax/MAPP composite exhibited 3.2\% and 3.3\% void contents compared to the flax/PP panels which showed higher void contents $6.2 \%$ and $8.1 \%$ (Table 1). Better mechanical properties of MAPP matrix composites were obtained due to the improved impregnation of flax by molten polymer in composites, which is confirmed by the SEM images in Figure 11. The SEM micrographs on the fracture face the samples (Figure 11) also showed a considerable matrix flow around the flax fibres in the case of flax/MAPP composites, where the flax fibres were better covered by the molten matrix compared to standard PP matrix.

To study the influence of maleic-anhydride grafted PP (MAPP) on the mechanical performance of flax/PP composites, the mechanical properties of composites samples were compared. Because the flax fibre contains functional hydroxyl groups that are able to interact chemically with the MAPP [17], the 

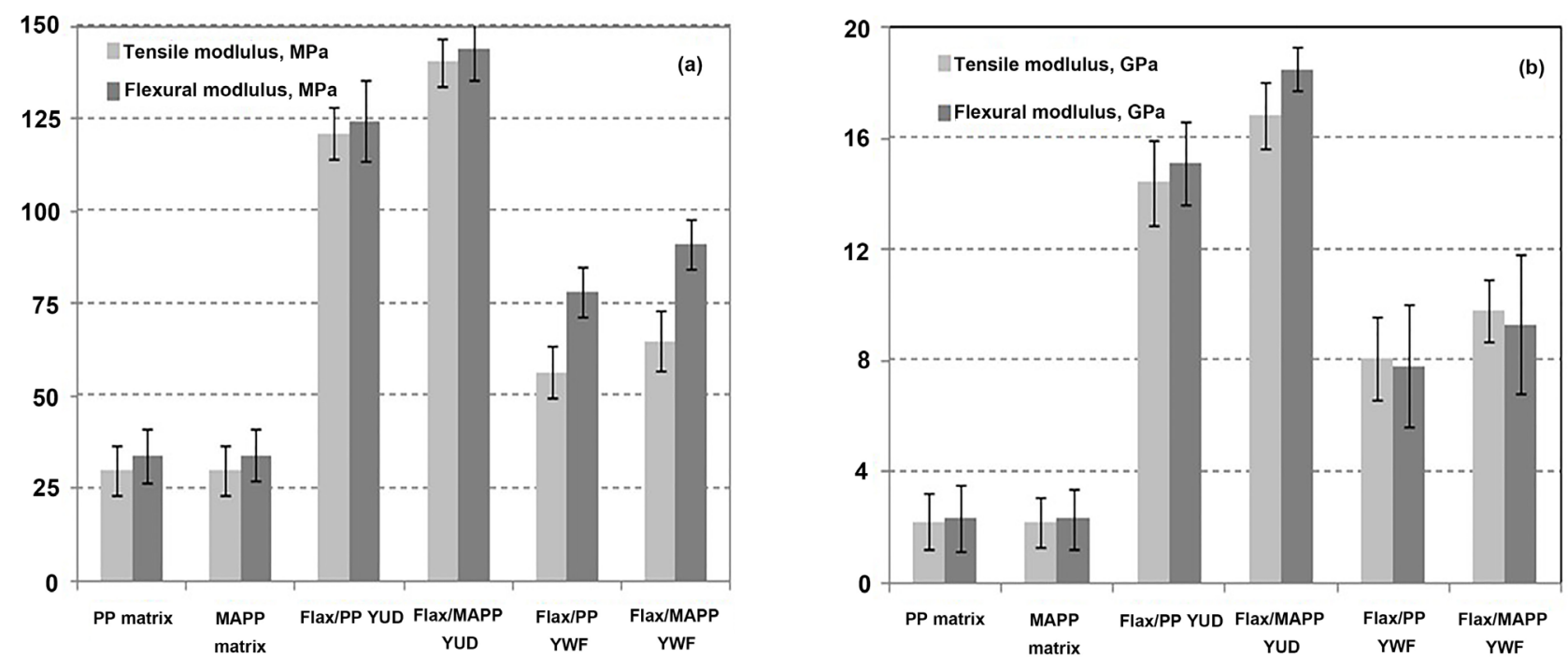

Figure 10. Mechanical (tensile and flexural) properties of PP, MAPP, Flax/PPYUD, Flax/MAPPYUD, Flax/PPYWF and Flax/ MAPPYWF samples.
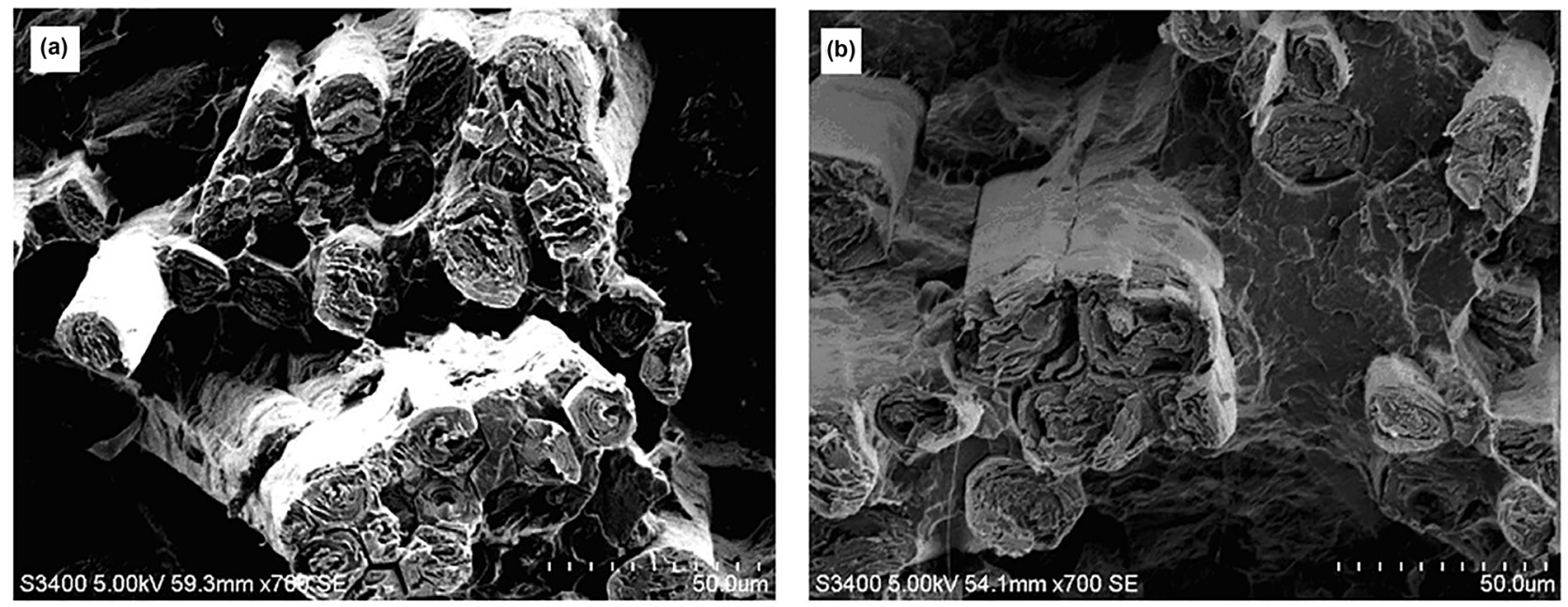

Figure 11. SEM images of fractured composite specimens: (a) flax/PP and (b) flax/MAPP.

Table 4. Measured and calculated strength and Young's modulus of UD composites.

\begin{tabular}{ccccc}
\hline Composite & $\begin{array}{c}\text { Measured tensile } \\
\text { strength(MPa) }\end{array}$ & $\begin{array}{c}\text { Calculated tensile strength } \\
\text { from rule of mixtures (MPa) }\end{array}$ & $\begin{array}{c}\text { Measured Young's } \\
\text { modulus (GPa) }\end{array}$ & $\begin{array}{c}\text { Calculated Young's modulus } \\
\text { from rule of mixtures (GPa) }\end{array}$ \\
\hline Flax/PPYUD & 121.0 & 209.4 & 16.3 & 23.52 \\
Flax/MAPPY UD & 140.5 & 209.4 & 19.5 & 23.52 \\
\hline
\end{tabular}

interfacial bonding/adhesion strength between the flax fibre and the modified PP (MAPP) has been significantly improved owing to better impregnation of the flax fibre by molten MAPP matrix. By inspecting the composites produced, distinctively surface smoothness appearances were observed between the composite panels made from the flax/PP and flax/MAPP. The panels made of flax/MAPP yarns exhibited better surface finish than that of flax/PP panels. In the case of 

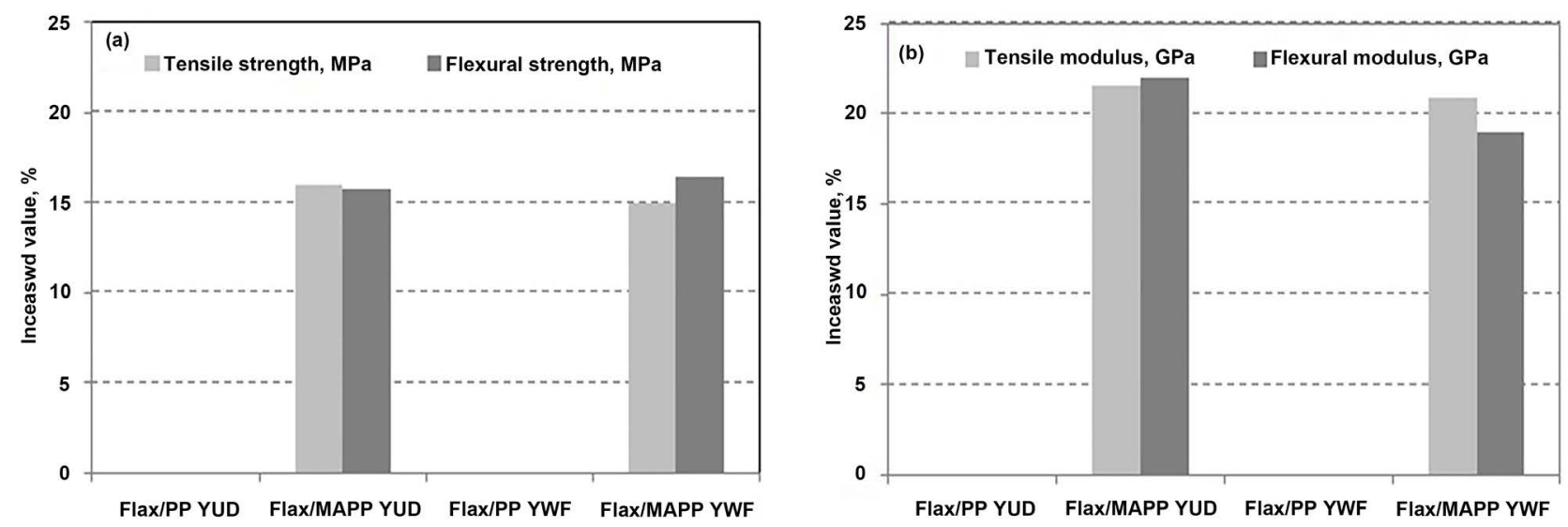

Figure 12. Comparison charts, extracted from Figure 10, to show the improved tensile and flexural properties of flax/MAPP compared to flax/PP composites: (a) Strength and (b) Modulus.

UD composites made from MAPP fibres it is found that both tensile and flexural strengths have increased by $16.0 \%$ (Figure $12(\mathrm{a})$ ). Also, the significant improvements were found in their moduli, where both tensile and flexural moduli have increased by $23 \%$ for flax/MAPP compared to flax/PP composite specimens (Figure 12(b)). Similar trends were also seen for the flax/MAPP yarn woven composite compared to flax/PP yarn woven fabric composites (Figure 12(a), Figure 12(b)).

As the fibre length and volume $\%$ of flax in both composites are same, the significant improvement in flax/MAPP composites was due to improved interfacial strength between the flax fibre and MA grafted PP. With respect to the high MFI value of MAPP, higher wettability of the flax fibres was also achieved during the moulding process, resulted in lower voids in the flax/MAPP composites compared to flax/PP composites. Moreover, the hydroxyl groups (-OH) of flax fibres have also contributed to improve fibre-matrix interface with MA grafted PP that enhanced the stiffness property of Flax/MAPP composites.

\section{Conclusion}

This work suggested that melaic anhydride grafted PP (MAPP) staple fibres can be used as viable and cost-effective alternative method of matrix fibre to improve the mechanical properties of natural fibre thermoplastic composites. The MAPP matrix staple fibres can be used in twist-less commingled yarn structures, blended with flax and other natural fibres. From the rheological studies, it is found that the MAPP fibre has higher melt flow rate and lower share viscosity resulting in flax/MAPP composites of enhanced mechanical properties compared to flax/standard PP composites. Modulus and strength of flax/MAPP composite improved by $25 \%$ and $15 \%$ compared to those manufactured from flax/PP blend.

\section{Conflicts of Interest}

The authors declare no conflicts of interest regarding the publication of this paper. 


\section{References}

[1] Goutianos, S. and Peijs, T. (2003) The Optimisation of Flax Fibre Yarns for the Development of High-Performance Natural Fibre Composites. Advanced Composites Letters, 12, 1237-241. https://doi.org/10.1177/096369350301200602

[2] Chapple, S., Ananadjiwala, R. and Thermo, J. (2010) Flammability of Natural Fibre-Reinforced Composites and Strategies for Fire Retardancy: A Review. Journal of Thermoplastic Composite Materials, 23, 871-893. https://doi.org/10.1177/0892705709356338

[3] Alimuzzaman, S., Gong, R.H. and Akonda, M.H. (2013) Nonwoven Polylactic Acid and Flax Biocomposites. Polymer Composites, 34, 611-1619. https://doi.org/10.1002/pc.22561

[4] Akonda, M.H. and Weager, B. (2011) Highly Aligned Natural Fibre Spread Sheet for Ultra-Lightweight Composite Structures. 4th International Conference on Sustainable Materials, Polymers and Composites, Birmingham, 8-11 July 2011.

[5] Olesen, P.O. and Plackett, D.V. (1999) Perspectives on the Performance of Natural Plant Fibres. Natural Fibres Performance Forum, Copenhagen, 27-28 May 1999, Denmark, 1-7.

[6] Van de Weyenberg, I., Ivens, J., De Coster, A., Kino, B., Baetens, E. and Verpoest, I. (2003) Influence of Processing and Chemical Treatment of Flax Fibers on Their Composites. Composites Science and Technology, 63, 1241-1246. https://doi.org/10.1016/S0266-3538(03)00093-9

[7] Khalil, H.P.S.A., Rozman, H.D., Ismail, H. and Ahmad, M.N. (2001) The Effect of Acetylation on Interfacial Shear Strength between Plant Fibres and Various Matrices. European Polymer Journal, 37, 1037-1045. https://doi.org/10.1016/S0014-3057(00)00199-3

[8] Lu, J.Z., Wu, Q. and McNabb, H.S. (2000) Chemical Coupling in Wood Fiber and Polymer Composites: A Review of Coupling Agents and Treatments. Wood and Fiber Science, 32, 88-104.

[9] Valadez-Gonzalez, A., Cervantes-Uc, J.M., Olayo, R. and Herrera-Franco, P.J. (1999) Effect of Fiber Surface Treatment on the Fiber-Matrix Bond Strength of Natural Fiber Reinforced Composites. Composites Part B: Engineering, 30, 309-320. https://doi.org/10.1016/S1359-8368(98)00054-7

[10] Bos, H.L., Mussig, J. and Van den Oever, M.J.A. (2006) Mechanical Properties of Short Flax Fibre Reinforced Compounds. Composites Part A: Applied Science and Manufacturing, 37, 1591-1604. https://doi.org/10.1016/j.compositesa.2005.10.011

[11] Espert, A., Vilaplana, F. and Karlsson, S. (2004) Comparison of Water Absorption in Natural Cellulosic Fibres from Wood and One-Year Crops in Polypropylene Composites and Its Influence on Their Mechanical Properties. Composites Part A: Applied Science and Manufacturing, 35, 1267-1276. https://doi.org/10.1016/j.compositesa.2004.04.004

[12] Malkapuram, R., Kumar, V. and Negi, Y.S. (2009) Recent Development in Natural Fibre Reinforced Polypropylene Composites. Journal of Reinforced Plastics and Composites, 28, 1169-1189. https://doi.org/10.1177/0731684407087759

[13] Keener, T.J., Stuart, R.K. and Brown, T.K. (2004) Maleated Coupling Agents for Natural Fibre Composites. Composites Part A: Applied Science and Manufacturing, 35, 357-362. https://doi.org/10.1016/j.compositesa.2003.09.014

[14] Felix, J.M. and Gatenholm, P. (1991) The Nature of Adhesion in Composites of Modified Cellulose Fibers and Polypropylene. Journal of Applied Polymer Science, 
42, 609-620. https://doi.org/10.1002/app.1991.070420307

[15] Lu, J.Z., Wu, Q. and Negulescu, I.I. (2001) The Influence of Maleation on Polymer Absorption and Fixation, Wood Surface Wettability, and Interfacial Bonding Strength in Wood-PVC Composites. Wood and Fiber Science, 34, 434-459.

[16] Mohebby, B., Fallah-Moghadam, P., Ghotbifar, A.R. and Kazemi-Najafi, S. (2011) Influence of Maleic-Anhydride-Polypropylene (MAPP) on Wettability of Polypropylene/Wood Flour/Glass Fiber Hybrid Composites. Journal of Agricultural Science and Technology, 13, 877-884.

[17] Hitchcock, A.P. (2001) Soft X-Ray Spectromicroscopy of Polymers and Bio-Polymer Interfaces. Journal of Synchrotron Radiation, 8, 66-71. https://doi.org/10.1107/S0909049500016447

[18] Jiang, J. and Chen, N. (2012) Preforms and Composites Manufactured by Novel Flax/Polypropylene Cowrap Spinning Method. Journal of Composite Materials, 46, 2097-2109. https://doi.org/10.1177/0021998311430155

[19] Bernet, N., Michaud, V., Bourban, P.-E. and Manson., J.-A.E. (2001) Commingled Yarn Composites for Rapid Processing of Complex Shapes. Composites Part A: Applied Science and Manufacturing, 32, 1613-1626.

https://doi.org/10.1016/S1359-835X(00)00180-9

[20] Zhang, L. and Miao, M. (2010) Commingled Natural Fibre/Polypropylene Wrap spun Yarns for Structured Thermoplastic Composites. Composites Science and Technology, 70, 130-135. https://doi.org/10.1016/j.compscitech.2009.09.016

[21] Darshil, U.S., Peter, J.S. and Mike, J.C. (2012) Modelling the Effect of Yarn Twist on the Tensile Strength of Unidirectional Plant Fibre Yarn Composites. Journal of Composite Materials, 47, 425-436. https://doi.org/10.1177/0021998312440737 